\title{
Media Pembelajaran Interaktif Geometri Molekul Kimia Menggunakan Augmented Reality Berbasis Android
}

\author{
Rifqi Mizan Aulawi* ${ }^{\star}$, Wing Wahyu Winarno, Asro Nasiri \\ Fakultas MIPA, Program Studi S2 Teknik Informatika \\ Universitas AMIKOM Yogyakarta \\ *Email: *rifqi.aulawi@students.amikom.ac.id \\ wing@amikom.ac.id \\ asro@amikom.ac.id
}

\begin{tabular}{l} 
Info Artikel \\
\hline Kata Kunci : \\
Geometri molekul, \\
Augmented Reality, \\
Multimarker \\
Keywords: \\
Molecular geometry, \\
Augmented Reality, \\
Multimarker \\
Tanggal Artikel \\
Dikirim : 27 Februari 2019 \\
Direvisi : 4 Maret 2019 \\
Diterima : 8 April 2019
\end{tabular}

\begin{abstract}
Abstrak
Pelajaran kimia dikenal dengan materi yang memerlukan daya imajinasi ekstra. Rata-rata pelajar mempunyai tingkat pemahaman yang berbeda. Oleh karena itu pengajar perlu mencari media alternatif untuk meningkatkan minat dan pemahaman para pelajar. Salah satu media alternatif yang dapat dijadikan dalam pembelajaran kimia yakni teknologi Augmented Reality. Metode berbasis Android ini menyajikan pembelajaran dalam bentuk geometri molekul. Penelitian ini menggunakan pendekatan Interactive Multimedia System Design Development (IMSDD) untuk membangun sebuah aplikasi metode pembelajaran interaktif geometri molekul kimia berbasis Augmented Reality. Penelitian ini menghasilkan sebuah prototype aplikasi Augmented Reality geometri molekul yang mempunyai fitur menggunakan multimarker. Fitur tersebut dapat menggabungkan beberapa marker atom menjadi bentuk geometri molekul $\mathrm{H}_{2} \mathrm{O}, \mathrm{BCl}_{2}$, $\mathrm{BeF}_{3}$, dan $\mathrm{NH}_{3}$. Tools untuk membangun aplikasi ini menggunakan Vuforia dan Unity3D. Hasil dari pengujian blackbox menunjukkan bahwa marker atom dan molekul yang terbentuk dari beberapa atom dapat terdeteksi dengan baik. Parameter yang diujikan meliputi deteksi marker, jarak, sudut dan pengaruh cahaya. Hasil analisis pengujian dapat disimpulkan bahwa multimarker dapat berjalan pada prototype aplikasi Augmented Reality geometri molekul namun hasil yang didapatkan marker harus dimodifikasi terlebih dahulu karena metode ini tidak dapat menggunakan marker sejenis (marker yang sama) seperti Hidrogen saja sehingga perlu dimodifikasi marker seperti marker Hidrogen 1, Hidrogen 2 dan Hidrogen 3.
\end{abstract}

\section{Abstarct}

Chemistry is well-known as a subject which requires high imagination. Students commonly have different level of understanding. Thus, teachers need to look for other alternatives to increase students' motivation and understanding in learning. One of the alternatives that can be used to learn Chemistry is Augmented Reality technology. This Android-based method provides learning material in the form of molecule geometry. This research uses Interactive Multimedia System Design Development (IMSDD) to create an Augmented-Reality-based application of interactive learning method of chemical molecule.

This research obtains a prototype of an Augmented-Reality-based application of molecule geometry of which feature uses multi-maker. The feature can combine some atomic markers into molecule geometry of $\mathrm{H}_{2} \mathrm{O}, \mathrm{BCl}_{2}, \mathrm{BeF}_{3}$, and $\mathrm{NH}_{3}$. The tools used to create this application 


\begin{abstract}
are Vuforia and Unity3D. The result of blackbox testing shows that atomic and molecular markers which are formed by some atoms can be detected properly. Parameter tested consists of detection of marker, distance, angle, and effect of light. Based on the result of the analysis, it can be concluded that multi-maker method works on the prototype of Augmented-Reality-based application of molecule geometry. However, the result of the marker should be modified first because this method cannot use the same type of marker such as Hydrogen only, so the marker needs to be modified like Hydrogen 1, Hydrogen 2, and Hydrogen 3.
\end{abstract}

\title{
1. PENDAHULUAN
}

Bentuk penyajian materi dalam dunia pendidikan dapat mempengaruhi tingkat penerimaan materi pada masing-masing pelajar. Banyak sekali penelitian yang menggunakan media interaktif untuk merubah bentuk penyajian materi dalam dunia pendidikan. Salah satunya yaitu Ismail [1] menggunakan media pembelajaran videoscribe untuk meningkatkan materi ikatan kimia. Berdasarkan penelitian ismail penggunaan media pembelajaran videoscribe memberikan pengaruh $19,85 \%$ terhadap peningkatan hasil belajar siswa. Penelitian Nurdin [2] menggunakan media pembelajaran macromedia flash 8 pada model pembelajaran kooperatif melalui pendekatan saintifik terhadap motivasi dan hasil belajar materi laju reaksi. Berdasarkan hasil Nurdin penggunaan media pembelajaran macromedia flash 8 berpengaruh terhadap motivasi dan hasil belajar siswa pada materi laju reaksi. Penelitian-penelitian tersebut membuktikan bahwa perlu adanya metode untuk meningkatkan pemahaman, motivasi dan penginkatan hasil belajar siswa menggunakan media interaktif untuk mencapai tujuan pembelajaran.

Augmented Reality (AR) merupakan salah satu teknologi yang berkembang saat ini, terbukti pada September 2018 lalu BEM Fakultas IImu Komputer Universitas Indonesia menyelenggarakan acara seminar yang bertajuk "Utilization of $A R$ VR in Digital Business" dalam acara puncak COMPFEST yang ke-10 di Universitas Indonesia menyatakan bahwa sampai tahun 2018 terdapat kurang lebih 1000 perusahaan yang berkecimpung dalam penggunaan teknologi tersebut [3]. AR memberikan gambaran kepada pengguna tentang penggabungan dunia nyata dengan dunia maya dilihat dari tempat yang sama. AR memiliki tiga karakteristik yaitu bersifat interaktif (meningkatkan interaksi dan persepsi pengguna dengan dunia nyata), menurut waktu yang nyata (real time) dan berbentuk 3 dimensi [4]. Hadirnya teknik AR diharapkan pelajar dapat membayangkan objek yang dijelaskan oleh guru maupun dosen. Adapun beberapa hasil penelitian teknologi AR sebagai pendukung penelitian ini adalah sebagai berikut:

Penelitian Widodo [5], membahas tentang pembuatan aplikasi pembelajaran ikatan kimia dengan teknologi AR. Penelitian ini menggabungkan beberapa unsur kimia menggunakan beberapa marker. Unsur tersebut akan bergabung dengan unsur lain (berinteraksi) ketika beberapa marker didekatkan. Proses interaksi marker tersebut berjalan dengan baik akan tetapi kelemahan terletak pada penggabungan unsur. Penggabungan unsur tersebut masih tidak beraturan sehingga membutuhkan teori penggabungan kimia secara teoritis. Selain itu penelitian ini hanya fokus pada penggabungan unsur kimia saja tidak dilanjutkan pada teori geometri.

Rajmah [6], penelitian ini membuat aplikasi alchemist menggunakan Augmented Reality berbasis Android untuk pembelajaran kimia SMA. Pembuatan aplikasi ini bertujuan untuk melengkapi kekurangan buku dan alat peraga kimia yang terbatas dengan memanfaatkan teknologi Augmented Reality. Saran dari penelitian ini yaitu agar dapat mengembangkan penelitian mengenai AR dengan menambah senyawa bukan hanya hidrokarbon. Kelemahan penelitian ini yakni pembuatan senyawa yang terbatas dengan menggunakan marker dan minimnya interaksi antar marker, sehingga penelitian yang perlu dikembangkan yakni membuat marker yang lebih interaktif. Penggabungan antar marker diharapkan menjadikan sebuah terobosan pembuatan senyawa dan geometri molekul yang dapat dieksplor lebih dalam.

Hafidha [7], melakukan penelitian tentang membangun aplikasi AR Sistem Periodik Unsur kimia SMA berbasis Android. Hasil penelitian mengatakan bahwa 80\% responden menyatakan aplikasi AR sangat baik menjadi bahan pertimbangan pada bidang ilmu kimia sehingga dapat diterima oleh masyarakat. Metode perancangan aplikasi pada penelitian ini yakni menggunakan metode waterfall dan pembuatan aplikasi menggunakan software Unity3D dan Vuforia. Adanya jumlah soal-soal dalam fasilitas AR yang dibuat membuat resource memori menjadi besar. Peneliti mengatakan bahwa aplikasi ini dapat dilakukan pengembangan pada objek 3D menjadi lebih menarik, lebih interaktif dengan menambahkan animasi. 
Cai [8], penelitian ini mempunyai tujuan yaitu mengembangkan alat pembelajaran AR berbasis inquiry untuk kimia SMP, menguji efek kognitif pada siswa, membandingkan dampaknya pada siswa berprestasi tinggi dan rendah dan meneliti sikap siswa terhadap perangkat lunak. Softwareyang digunakan meliputi NyARToolkit, Java3D dan JMF (Java Media Framework). Instrumen pengukuran pada penelitian ini menggunakan pre-post test, instruction and activity form, post questionnaire, dan interview protocol. Hasil penelitian menyatakan bahwa AR bermanfaat dalam meningkatkan kinerja tes kognitif siswa SMP serta memiliki pengaruh yang relatif lebih besar pada siswa berprestasi rendah. Peneliti merancang $A R$ berbasis $\mathrm{PC}$ dengan menggunakan webcam sebagai penangkap marker sehingga siswa sangat terbatas dalam mengeksplorasi teknologi AR. Beda halnya jika siswa dapat bereksplorasi via smartphone, selain dapat diakses dirumah, siswa juga dapat belajar dimana saja karna lebih efisien dibawa. Peneliti menyarankan untuk mengembangkan AR sebagai alat pembelajaran dengan memperluas metode serta materi kimia SMP, sehingga tidak mengharuskan siswa untuk menghafal struktur dan konsep kimia secara abstrak.

Berdasarkan kutipan di atas dapat disimpulkan bahwa terdapat beberapa kelemahan dari penelitian-penelitian tersebut. Penelitian ini akan merancang interaksi antar marker untuk menyusun reaksi kimia sehingga membentuk ikatan kimia dan konsep geometri molekul, sehingga dibutuhkan perulangan pemanggilan objek dalam sistem yang akan dirancang. Oleh karena itu penelitian ini menggunakan metode multimarker untuk menggabungkan beberapa marker atom menjadi senyawa geometri molekul dan diharapkan dapat menjadi media pembelajaran interaktif geometri molekul kimia yang lebih mudah dipelajari, dipahami dan dikembangkan.

Tujuan dari penelitian ini diantaranya yakni menjadi alternatif media pembelajaran geometri molekul kimia. Selain itu merancang dan memanfaatkan multimarker pada aplikasi media pembelajaran interaktif geometri molekul kimia menggunakan Augmented Reality berbasis Android. Selain itu manfaat penelitian ini yakni menambah pengetahuan bagi pengembang Augmented Reality sehingga dapat dikembangkan untuk metode pembelajaran dibidang kimia dan dapat digunakan sebagai standar media baru pada media pembelajaran kimia yang interaktif.

\section{METODE PENELITIAN}

Jenis marker yang digunakan dalam penelitian ini adalah Marker based trackingyang ada pada Vuforia. Marker kemudian diuji dengan software prototype AR Geometri yang diciptakan oleh peneliti. Hasil menunjukkan bahwa marker tidak terbentuk stabil, sehingga peneliti memodifikasi marker tersebut yang awalnya polos menjadi berpola lurik. Hal ini dilakukan untuk membedakan antara jenis marker atom yang digunakan.

Metode penelitian yang digunakan pada penelitian ini yaitu jenis metode pengembangan. Menurut Sugiyono [9], metode penelitian dan pengembangan dapat diartikan sebagai cara ilmiah untuk meneliti, merancang, memproduksi dan menguji validitas produk yang telah dihasilkan. Berdasarkan pengertian tersebut, kegiatan penelitian dan pengembangan dapat disingkat menjadi 4P (Penelitian, Perancangan, Produksi dan Pengujian). Menurut teori tersebut penulis menggunakan IMSDD sebagai metode perancangannya karena metode tersebut sudah mencakup nilai 4P.

Metode IMSDD (Interactive Multimedia System Design Development) dikembangkan oleh Dastbaz. Menurut Dastbaz [10], sistem multimedia interaktif membutuhkan pendekatan rinci dan terencana baik terhadap masalah integrasi media. Metode IMSDD menangani perpaduan berbagai media seperti audio, video, animasi, teks dan grafik. Adapun siklus model IMSDD dapat dilihat pada Gambar 1.

Metode pada Gambar 1. meliputi System Requirements, Design Consideration, Implementation, dan Evaluation. Tahapan-tahapan tersebut sebagai berikut :

1. System Requirement

Pada tahap ini dilakukan analisis kebutuhan sistem yang meliputi definisi sistem kebutuhan dan profil pengguna, kebutuhan hardware software, serta pertimbangan penyebaran sistem.

2. Design Consideration

Tahap ini dilakukan perancangan terhadap sistem yang akan dibuat meliputi metafora design, format dan tipe informasi, struktur navigasi, dan UML.

3. Implementation

Tahapan ini melakukan pengujian terhadap prototype. Pengujian dilakukan dengan Blackbox testing yang berfokus pada kebutuhan fungsional program, berupa kesesuaian output aplikasi dengan input yang diterima aplikasi.

4. Evaluation. 
Tahap ini menggunakan evaluasi formatif, yaitu prototype divalidasi oleh ahli materi dan ahli media. Evaluasi terhadap sistem yang telah dibuat menggunakan angket yang mencakup angket ahli media dan angket ahli materi untuk memastikan sistem yang diuji dapat terpenuhi sesuai dengan konsep yang diharapkan.

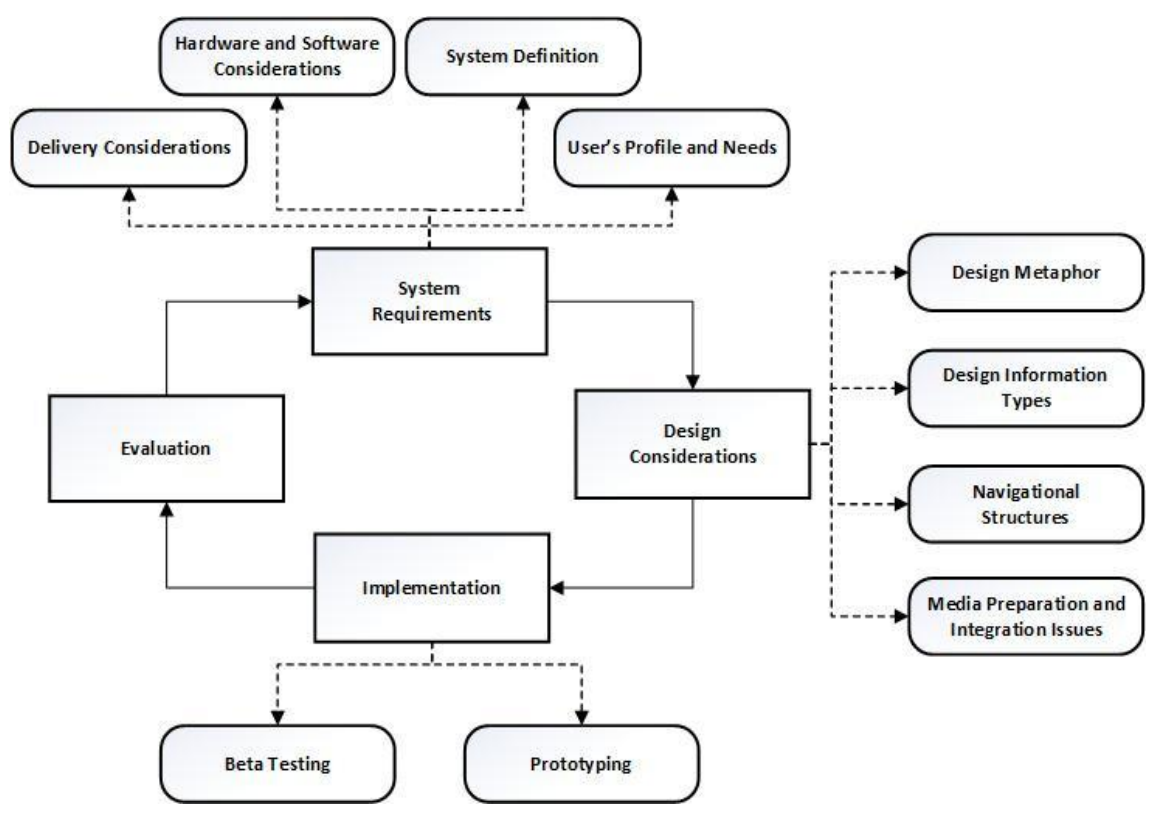

Gambar 1. Siklus IMSDD [10]

\subsection{UML (Unified Modeling Language)}

Pada tahap selanjutnya peneliti mengembangkan dengan mengunakan UML (Unified Modeling Language) sebagai gambaran sistem yang meliputi use case diagram, dan activity diagram.

\subsubsection{Use case diagram}

Use case diagram pada gambar di bawah ini menunjukkan proses-proses pada sistem Augmented Realityyang akan dibuat, dimana user dapat mengendalikan marker pada menu scan marker yang ada pada tampilan menu AR serta mengetahui informasi terkait bentuk geometri molekul.

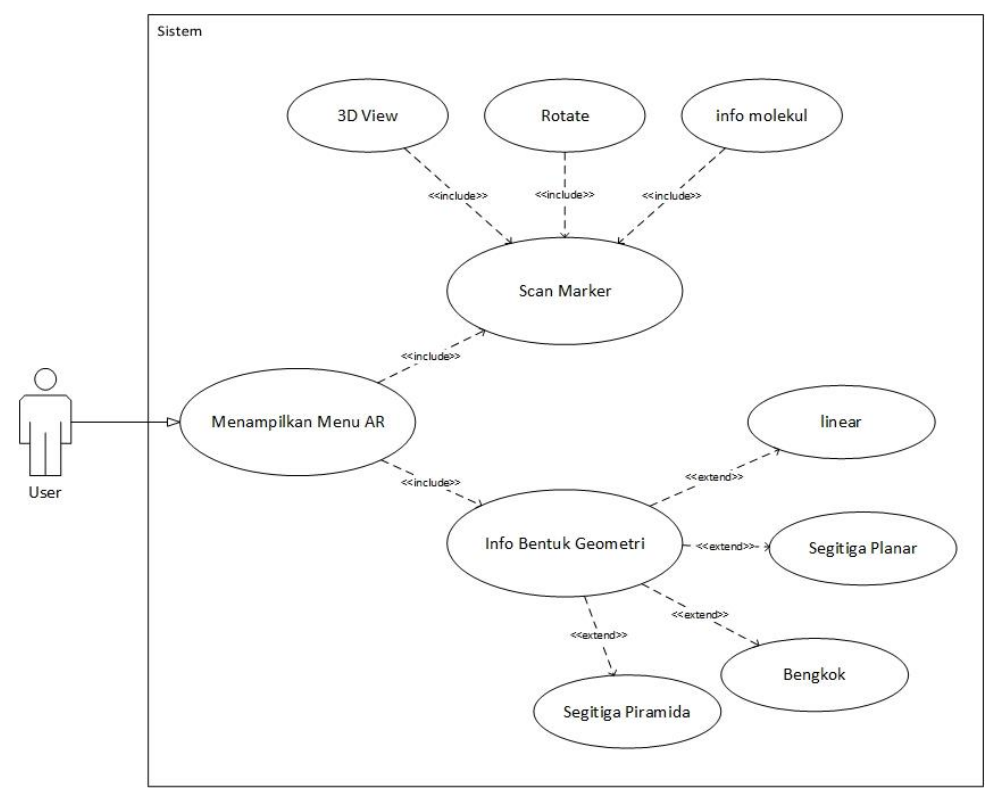

Gambar 2. Use case Diagram 


\subsubsection{Activity diagram}

Activity diagram pada gambar di bawah ini menunjukkan aktivitas yang dilakukan user pada sistem Augmented Reality, dimana user dapat memindai marker dalam sistem sesuai marker yang diinginkan dan menambahkan marker dengan cara mendekatkan marker ke kamera. Setelah marker terdeteksi oleh sistem, sistem akan menampilkan bentuk/objek 3D dan akan bergabung dengan objek lainnya ketika marker didekatkan sesuai dengan bentuk geometri yang sudah ada.

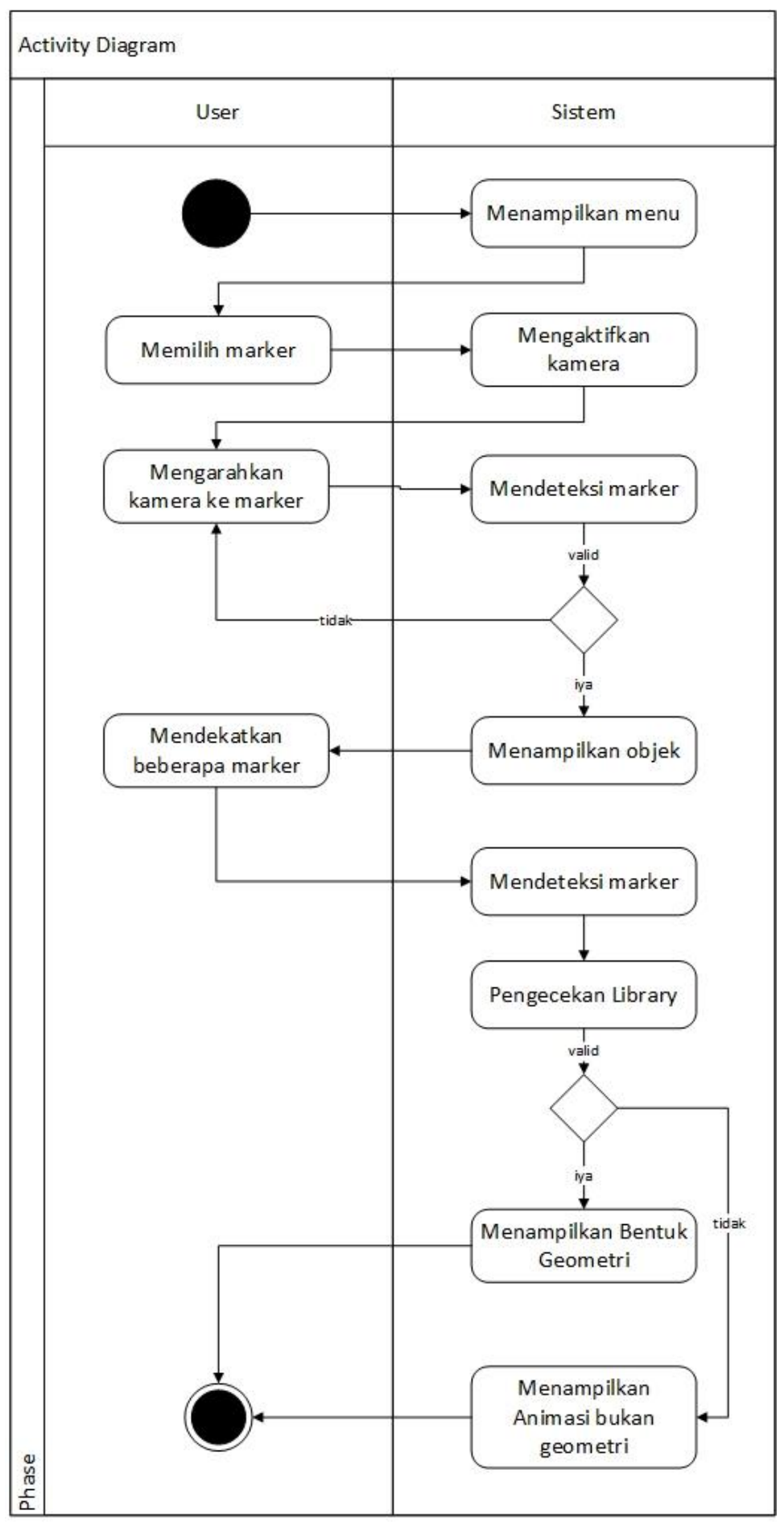

Gambar 3. Activity Diagram 


\subsection{Metode Pengumpulan Data}

Metode pengumpulan data yang digunakan untuk mengumpulkan informasi yang dibutuhkan untuk membangun aplikasi Augmented Reality Geometri Molekul kimia dalam penelitian ini yaitu:

1. Studi Pustaka

Studi pustaka yang dilakukan yaitu dengan mengumpulkan data dan sumber informasi dari buku, jurnal, internet maupun literature lainnya yang membantu dalam perancangan dan implementasi teknologi Augmented Reality.

2. Wawancara

Peneliti mewawancarai beberapa narasumber yang ahli dalam bidang kimia secara langsung.

3. Observasi

Dalam observasi ini, peneliti secara langsung terlibat dalam kegiatan sehari-hari orang atau situasi yang diamati sebagai sumber data. Dalam penelitian ini akan dilakukan pengamatan dan pencatatan fenomena-fenomena yang terjadi dalam aktivitas pada mahasiswa kimia.

4. Angket

Angket atau kuesioner merupakan suatu teknik atau cara pengumpulan data secara tidak langsung. Angket dilakukan untuk mengevaluasi kualitas dan kelayakan produk.

\subsection{Metode Analisis Data}

Metode yang digunakan dalam penelitian ini adalah analisa kuantitatif dengan pendekatan deskriptif. Metode penelitian kuantitatif merupakan jenis penelitian yang sistematis, terencana dan terstruktur dengan jelas. Menurut Sugiyono [11], metode penelitian kuantitatif dapat diartikan sebagai metode penelitian yang berlandaskan pada filsafat positivism, digunakan untuk meneliti populasi atau sampel tertentu, teknik pengambilan sampel pada umumnya dilakukan secara random, pengumpulan data menggunakan instrumen penelitian, analisis data bersifat kuantitatif/statistic dengan tujuan untuk menguji hipotesis yang telah ditetapkan. Adapun pengertian deskriptif menurut Sugiyono [11], adalah metode yang berfungsi untuk mendeskripsikan atau memberi gambaran terhadap objek yang diteliti melalui data atau sampel yang telah terkumpul sebagaimana adanya, tanpa melakukan analisis dan membuat kesimpulan yang berlaku umum.

Metode untuk mengetahui kelayakan produk dari instrumen peneliti mengubah penilaian dalam bentuk kualitatif menjadi kuantitatif. Kriteria penilaian dalam penelitian dan pengembangan ini ditentukan dengan nilai minimal Baik (B) atau dengan interval 4. Adapun ketentuan penilaiannya menurut Sukardi [12] seperti Tabel 1. sebagai berikut :

Tabel 1. Pedoman Penilaian Skor

\begin{tabular}{cc}
\hline Data Kualitatif & Skor Interval \\
\hline Sangat Baik (SB) & 5 \\
\hline Baik (B) & 4 \\
\hline Cukup (C) & 3 \\
\hline Kurang (K) & 2 \\
\hline Sangat Kurang (SK) & 1 \\
\hline
\end{tabular}

Tabel 1. terdapat 5 poin penilaian dan dalam penelitian ini dibuat batasan nilai 100 , sehingga untuk mendapatkan nilai baik (B) dibutuhkan nilai minimal 80 dengan cara nilai maksimal 100 dibagi 5 (poin penilaian) dan didapatkan batasan nilai $S B=100, B=80, C=60, K=40, S K=20$.

\section{HASIL DAN PEMBAHASAN}

Tahap ini berupa perancangan, penerapan, analisis dan pengujian. Adapun objek yang akan dimunculkan pada layer ponsel adalah 1 - 4 objek atom dan perubahan beberapa interaksi geometri molekul sesuai dengan rumus $\mathrm{H}_{2} \mathrm{O}, \mathrm{BCl}_{2}, \mathrm{BeF}_{3}$, dan $\mathrm{NH}_{3}$.

\subsection{Perancangan Antarmuka}

Adapun perancangan Interface untuk aplikasi AR Geometri Molekul seperti Gambar 4. 


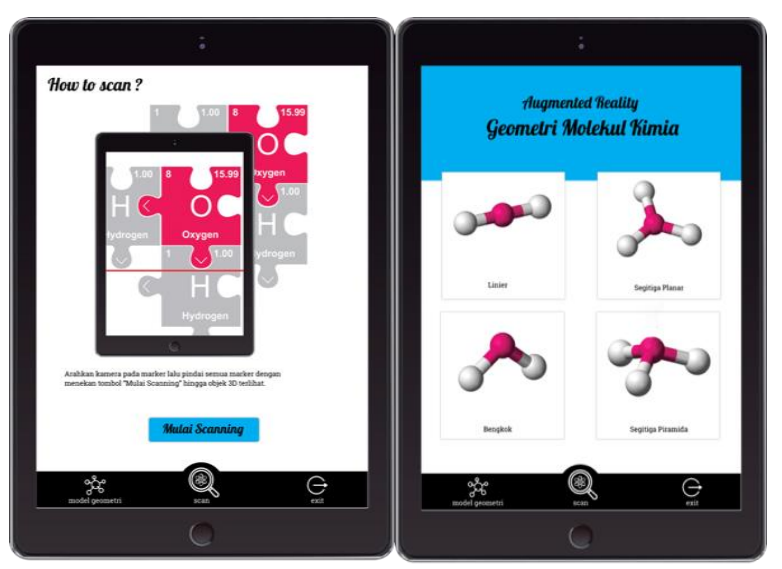

\section{Gambar 4. Gambar perancangan prototipe aplikasi AR Geometri Molekul}

Pada Gambar 4. menunjukkan bahwa terdapat tiga menu navigasi yakni model geometri, scan dan exit. Pada model geometri menunjukkan bentuk-bentuk geometri yang dapat terbentuk kedepannya menu tersebut akan memuat lebih banyak bentuk geometri dan informasi mengenai geometri molekul. Menu scan yaitu untuk memindai marker agar terbentuk objek atom dan geometri molekul. Pada menu tersebut di jelaskan bagaimana cara memindai marker agar objek tersebut dapat dipindai dengan baik. Menu exit berfungsi untuk keluar dari aplikasi AR Geometri Molekul. Perancangan interface ini dirancang agar user dapat mengoprasikan aplikasi secara menarik dan mudah.

\subsection{Perancangan Marker}

Design marker pada penelitian ini menggunakan software Corel Draw setelah itu design marker di upload ke database Vuforia. Marker berfungsi sebagai pemicu untuk munculnya objek atom maupun geometri molekul di layar ponsel. Design marker yang bagus agar memenuhi kriteria atau score yang bagus adalah marker yang memiliki banyak bagian, bagian-bagian tersebut terdistribusi secara merata diseluruh bagian gambar, jarak antar bagian kecil , objek-objek yang membentuk gambar memiliki sisi-sisi yang jelas dan kontras yang tajam terlihat berbeda. Designmarker yang dibuat akan diupload dan dinilai dalam Vuforia menggunakan layanan Target Management System (TMS) yg dapat memberikan nilai sebuah gambar dengan memberikan rating mulai dari bintang satu sampai bintang lima. Score bintang yang maksimal akan lebih bagus untuk pendeteksian marker. Marker yang dibuat yakni atom $\mathrm{H}, \mathrm{O}, \mathrm{B}, \mathrm{Cl}, \mathrm{Be}, \mathrm{N}$, dan $\mathrm{F}$. Adapun design marker sebagai berikut :

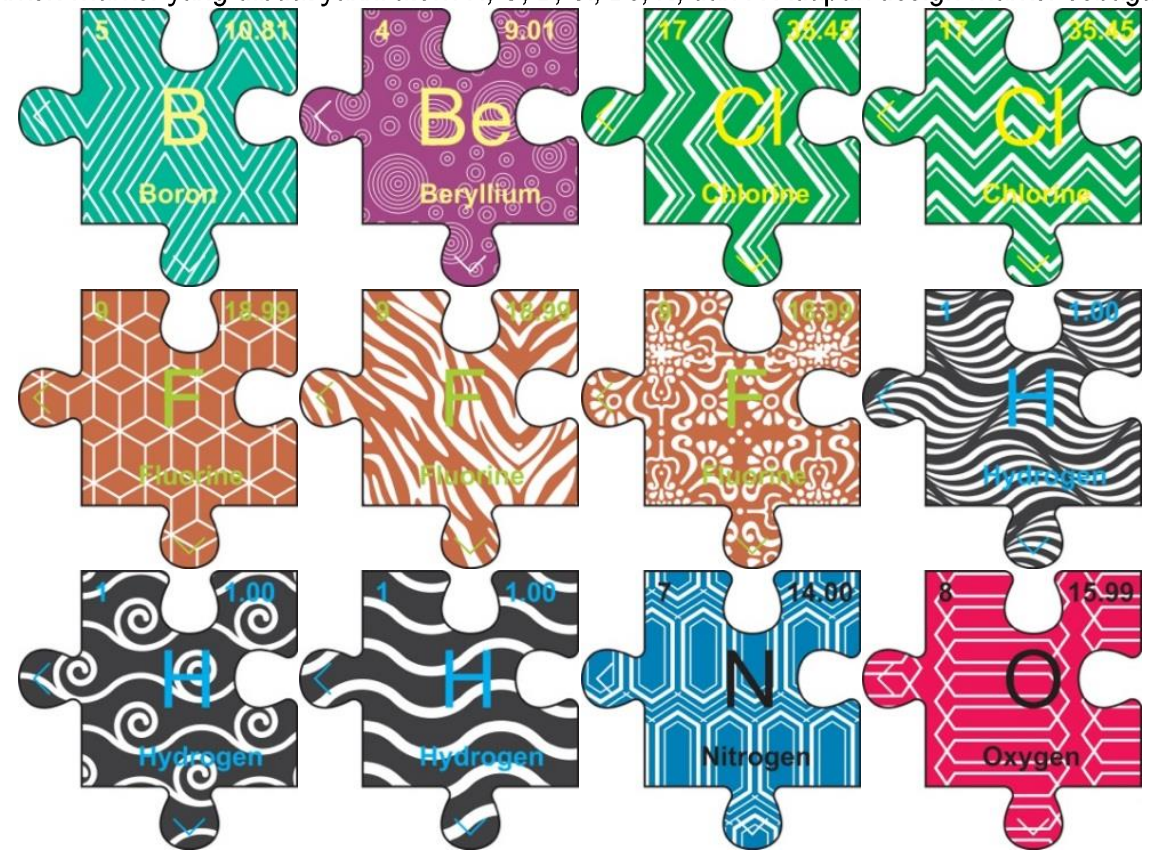

Gambar 5. Design marker atom 0ksigen 
Design marker atom pada Gambar 5. dibedakan antara atom Hidrogen 1, atom Hidrogen 2 dan atom Hidorgen 3 karena ketika design tersebut sama akan terjadi looping atom sehingga membuat aplikasi tersebut eror, hal ini juga dipengaruhi oleh keterbatasan pada sistem Vuforia. Keterbatasan sistem tersebut yakni ketika mengupload dua marker yang sama akan diabaikan oleh sistem vuforianya. Marker atom yang sejenis dan dibedakan bukan hanya Hidrogen $(\mathrm{H})$ saja tetapi pada marker atom Klorin (Cl) dan Fluor (F). Selain itu Design dari marker ini membentuk suatu puzzle yang diharapkan dapat dijadikan salah satu interaksi yang menarik bagi user.

\subsection{Perancangan Tekstur}

Perancangan tekstur pada penelitian ini sangat sederhana dikarenakan bentuk atom pada dasarnya bulat, halus dan berwarna solid. Pembuatan bentuk atom yang bulat ini dapat dibuat melalui menu createlalu 3D object dan pilih menu sphere. Pengambilan warna ini dilakukan melalui Adobe Photoshop lalu di eksport ke Unity3D. Adapun hasil dari perancangan tekstur dapat dilihat pada Gambar 6 :

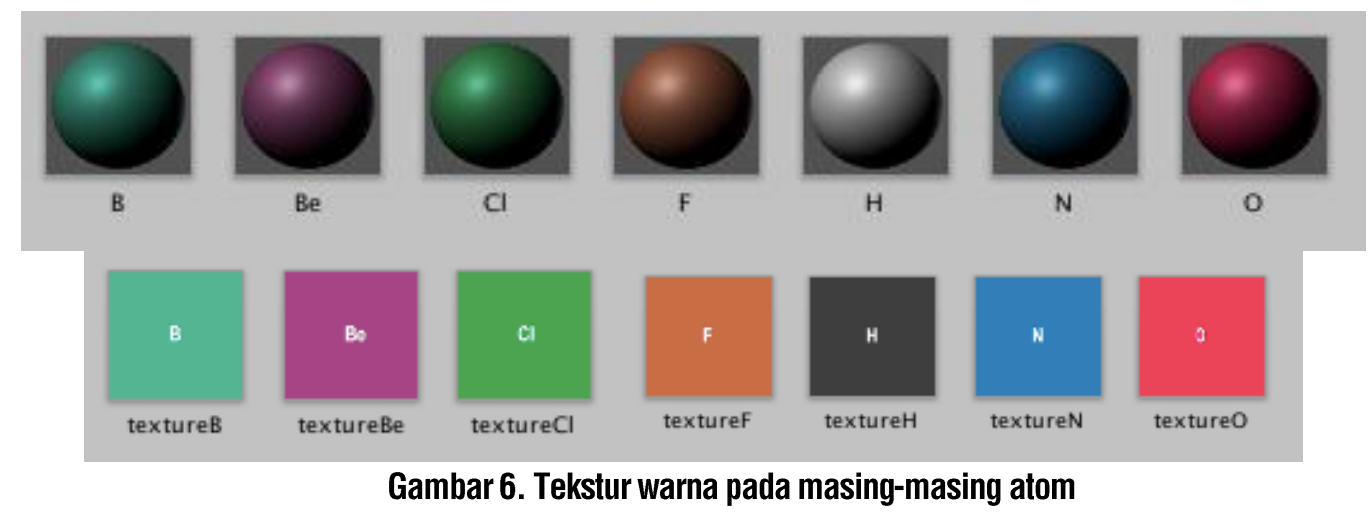

Pada Gambar 6. memperlihatkan bahwa tekstur yang akan dirancang berbentuk bulat dan berwarna solid. Tekstur warna atom diambil sesuai dengan warna standar atomnya. Atom 0 berwarna merah, $\mathrm{N}$ berwarna biru, $\mathrm{H}$ berwarna abu-abu, $\mathrm{F}$ berwarna kuning, $\mathrm{Cl}$ berwarna hijau, Be berwarna Ungu dan B berwarna hijau tosca.

\subsection{Penerapan Multimarker}

Tahap ini membuat script untuk menggabungkan atom-atom agar menjadi geometri molekul. Adapaun geometri molekul yang akan dibuat yaitu molekul $\mathrm{H}_{2} \mathrm{O}$ dengan geometri bengkok, molekul $\mathrm{BeCl}_{2}$ dengan geometri linier, molekul $\mathrm{BF}_{3}$ dengan geometri segitiga planar, dan molekul $\mathrm{NH}_{3}$ dengan geometri segitiga piramida. Sebelum ke tahap script tahap yang dilakuakan yaitu membuat bentuk molekul geometri $\mathrm{H}_{2} \mathrm{O}, \mathrm{BeCl}_{2}, \mathrm{BF}_{3}$, dan $\mathrm{NH}_{3}$. Pembentukan geometri molekul langkah-langkahnya hampir sama dengan pembentukan objek atom, hanya saja menambah penggabung antar molekul menggunakan 3D object $>$ cylinder. Adapun daftar bentuk-bentuk geometri molekul seperti Gambar 7. 


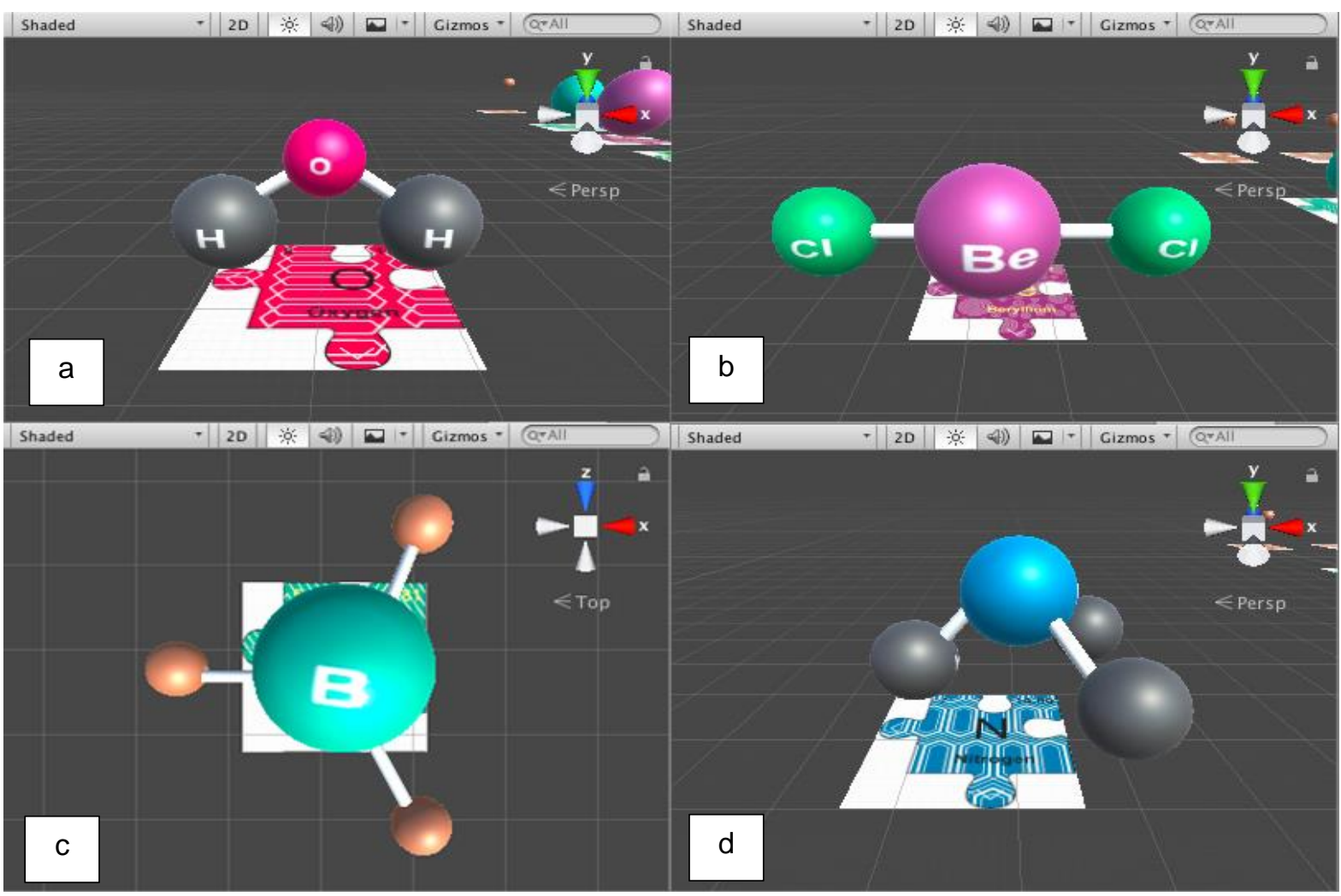

Gambar 7. Daftar bentuk geometri molekul (a) $\mathrm{H}_{2} \mathrm{O}$ (b) $\mathrm{BeCl}_{2}$ (c) $\mathrm{BF}_{3}$ (c) $\mathrm{NH}_{3}$

Setelah pembentukan geometri molekul selesai langkah selanjutnya yaitu membuat method untuk penggabungan atom agar menjadi sebuah geometri molekul. Adapun methodmasing-masing geometri molekul sebagai berikut:

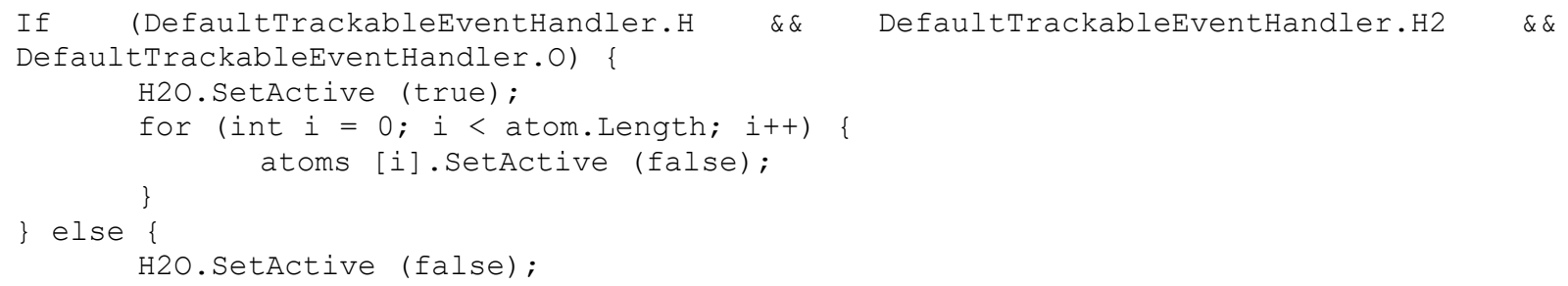

Pseudocode di atas menunjukkan bagaimana pembentukan geometri molekul $\mathrm{H}_{2} \mathrm{O}$. Script bagian pertama memeriksa apakah marker $\mathrm{H} 1, \mathrm{H} 2$ dan $\mathrm{O}$ terdeteksi. Jika marker $\mathrm{H1}, \mathrm{H} 2$ dan $\mathrm{O}$ terdeteksi maka molekul $\mathrm{H}_{2} \mathrm{O}$ akan aktif dan menonaktifkan atom-atom tunggal lainnya. Sebaliknya jika marker $\mathrm{H} 1, \mathrm{H} 2$ dan $\mathrm{O}$ tidak terdeteksi maka molekul $\mathrm{H}_{2} \mathrm{O}$ tidak diaktifkan.

\subsection{Pengujian Objek Atom}

Pengujian objek atom dilakukan untuk memastikan apakah objek dapat berjalan dengan lancar atau tidak pada aplikasi yang telah dirancang. Pengujian ini dilakukan pada ponsel Xiaomi Redmi Note 4 yang sudah terinstal aplikasi AR Geometri Molekul. Pengujian ini juga berfungsi untuk mendapatkan informasi mengenai kesalahan script atau komponen yang eror sehingga dapat dilakukan tindakan jika terjadi kesalahan. Adapun hasil pengujian objek atom dapat dilihat pada Tabel 2. 
Tabel 2. Hasil uji objek atom

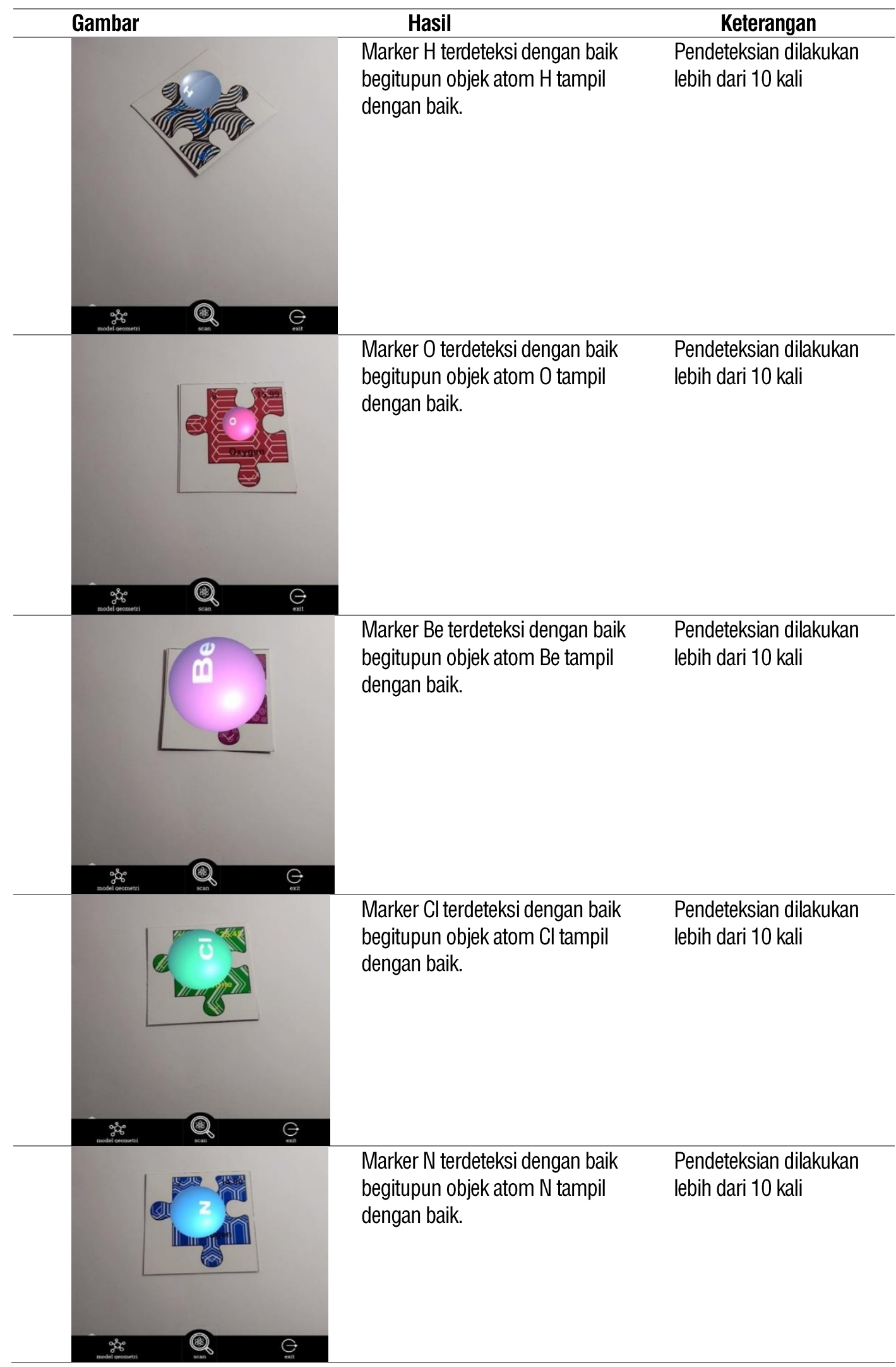




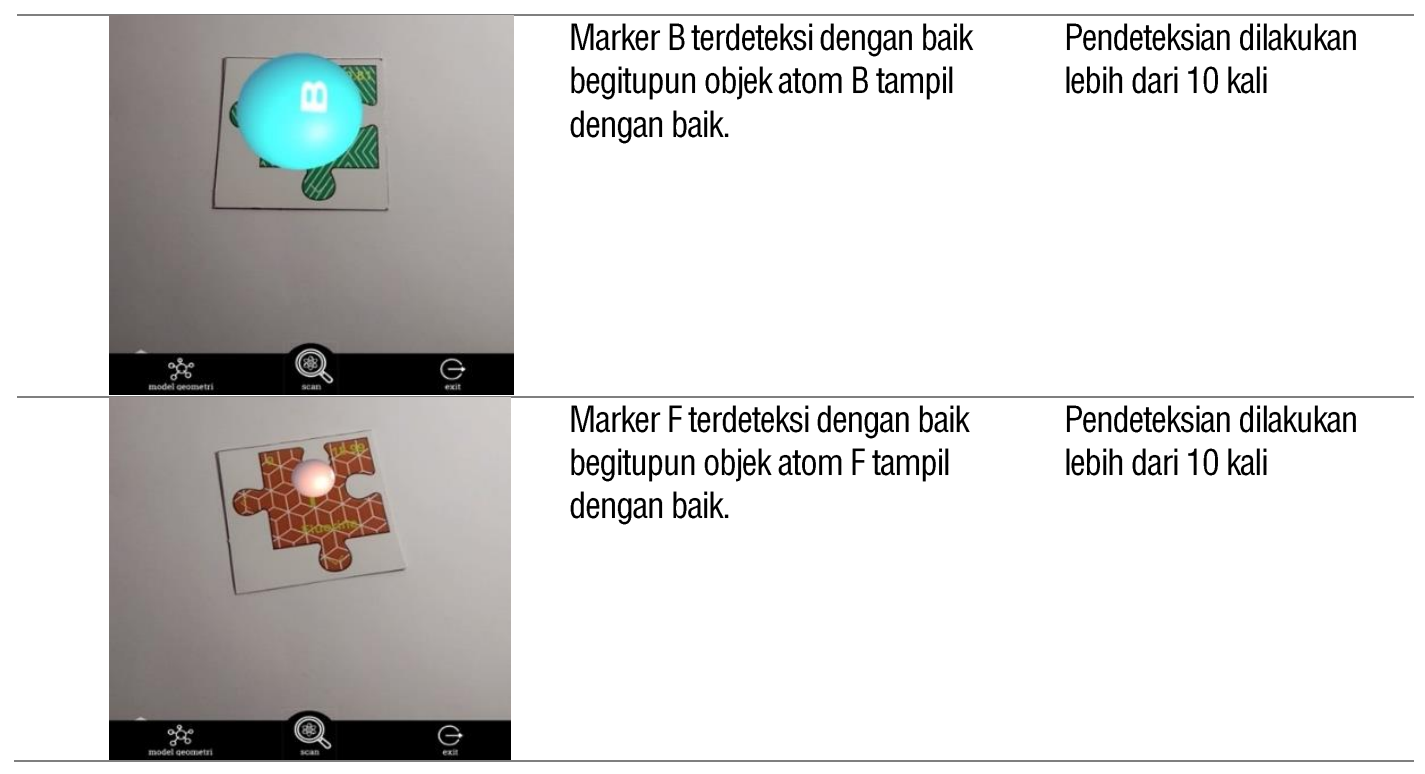

\subsection{Pengujian Objek Geometri Molekul}

Pengujian objek geometri molekul ini dilakukan tidak jauh berbeda dengan pengujian objek atom yakni untuk memastikan apakah objek dapat bergabung dan berjalan dengan lancar atau tidak pada aplikasi yang telah dirancang. Adapun hasil pengujian objek geometri molekul dapat dilihat pada Tabel 3 .

Tabel 3. Pengujian Geometri Molekul

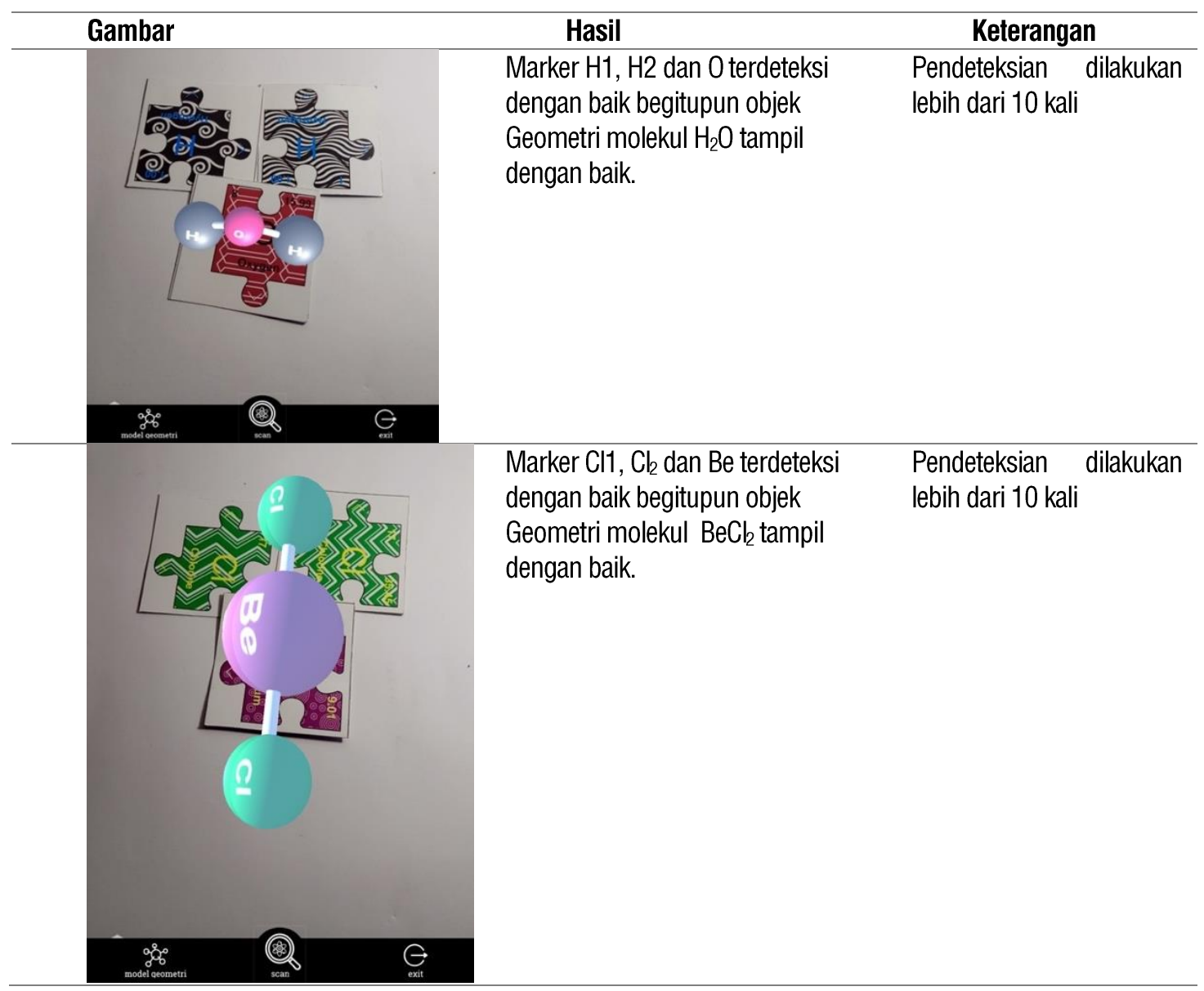




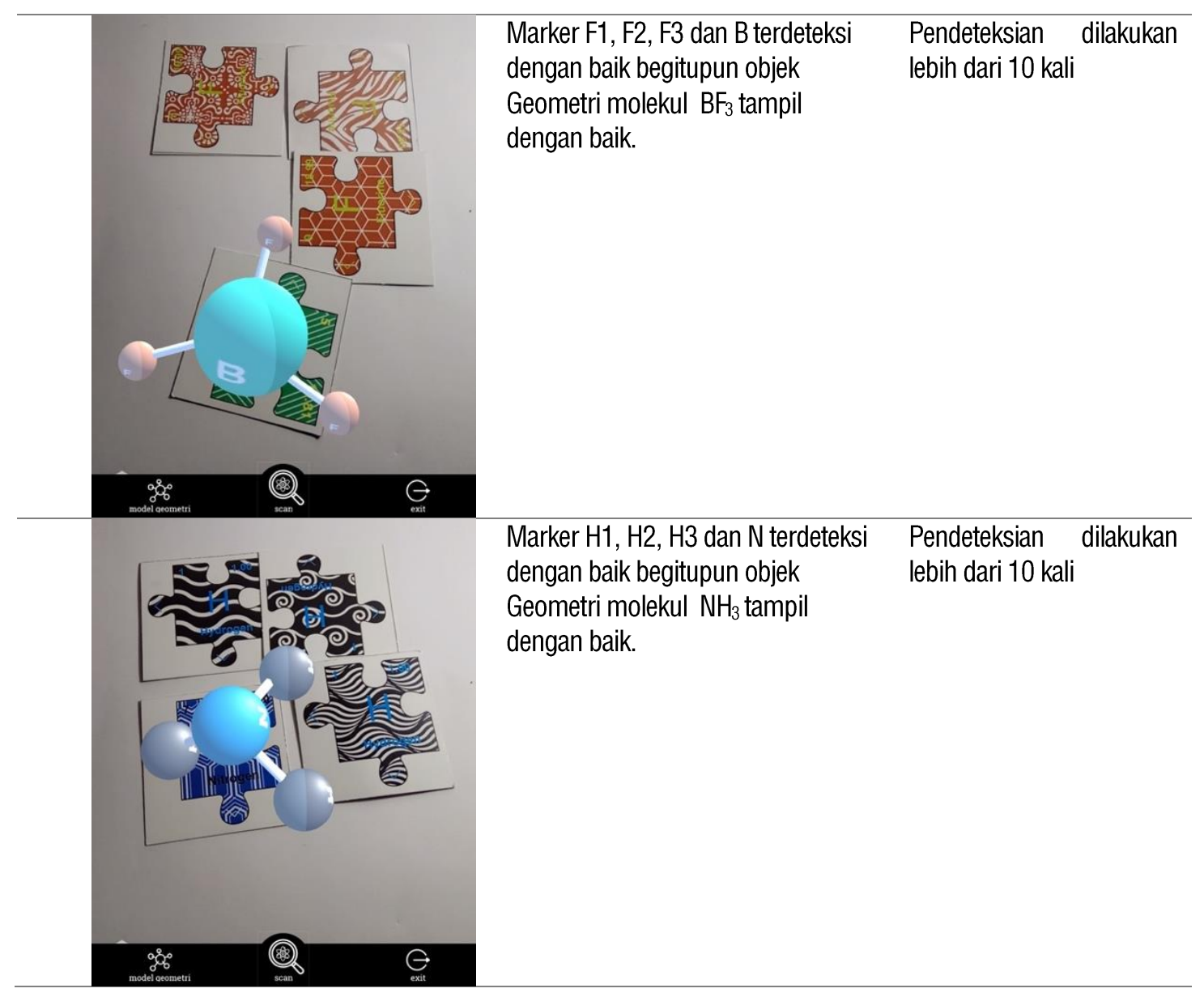

Tabel 4. Pengujian molekul dengan intensitas cahaya $\mathbf{1 2 5 0}$ lux

\begin{tabular}{|c|c|c|c|c|c|c|c|}
\hline \multicolumn{4}{|c|}{$\mathrm{H}_{2} \mathrm{O}$} & \multicolumn{4}{|c|}{$\mathrm{NH}_{3}$} \\
\hline \multirow[t]{2}{*}{ Jarak (cm) } & \multicolumn{3}{|c|}{ Sudut (derajat) } & Jarak (cm) & \multicolumn{3}{|c|}{ Sudut (derajat) } \\
\hline & 0 & 30 & 45 & & c & 30 & 45 \\
\hline 10 & $Y<1$ & $Y<1$ & $Y<1$ & 10 & $Y<1$ & $\mathrm{Y}<1$ & $Y<1$ \\
\hline 15 & $Y<1$ & $Y<1$ & $Y<1$ & 15 & $Y<1$ & $Y<1$ & $Y<1$ \\
\hline \multicolumn{4}{|c|}{$\mathrm{BeCl}_{2}$} & \multicolumn{4}{|c|}{$\mathrm{BF}_{3}$} \\
\hline \multirow[t]{2}{*}{ Jarak (cm) } & \multicolumn{3}{|c|}{ Sudut (derajat) } & Jarak (cm) & \multicolumn{3}{|c|}{ Sudut (derajat) } \\
\hline & 0 & 30 & 45 & & c & 30 & 45 \\
\hline 10 & $Y<1$ & $Y<1$ & $Y<1$ & 10 & $Y<1$ & $Y<1$ & $Y<1$ \\
\hline 15 & $Y<1$ & $Y<1$ & $Y<1$ & 15 & $Y<1$ & $Y<1$ & $Y<1$ \\
\hline
\end{tabular}

Tabel 5. Pengujian molekul dengan intensitas cahaya $\mathbf{5 5 0}$ lux

\begin{tabular}{|c|c|c|c|c|c|c|c|}
\hline \multicolumn{4}{|c|}{$\mathrm{H}_{2} \mathrm{O}$} & \multicolumn{4}{|c|}{$\mathbf{N H}_{3}$} \\
\hline \multirow[t]{2}{*}{ Jarak (cm) } & \multicolumn{3}{|c|}{ Sudut (derajat) } & \multirow[t]{2}{*}{ Jarak (cm) } & \multicolumn{3}{|c|}{ Sudut (derajat) } \\
\hline & 0 & 30 & 45 & & & 30 & 45 \\
\hline 10 & $Y<1$ & $Y<1$ & $Y>1$ & 10 & $Y<1$ & $Y<1$ & $Y>1$ \\
\hline 15 & $Y<1$ & $Y<1$ & $T$ & 15 & $Y<1$ & $Y<1$ & $T$ \\
\hline
\end{tabular}




\begin{tabular}{|c|c|c|c|c|c|c|c|}
\hline \multicolumn{4}{|c|}{$\mathrm{BeCl}_{2}$} & \multicolumn{4}{|c|}{$\mathrm{BF}_{3}$} \\
\hline \multirow[t]{2}{*}{ Jarak (cm) } & \multicolumn{3}{|c|}{ Sudut (derajat) } & \multirow[t]{2}{*}{ Jarak (cm) } & \multicolumn{3}{|c|}{ Sudut (derajat) } \\
\hline & 0 & 30 & 45 & & 0 & 30 & 45 \\
\hline 10 & $Y<1$ & $Y<1$ & $Y<1$ & 10 & $Y<1$ & $Y<1$ & $Y>1$ \\
\hline 15 & $Y<1$ & $Y<1$ & $Y<1$ & 15 & $Y<1$ & $Y<1$ & $\mathrm{~T}$ \\
\hline
\end{tabular}

Catatan :

$Y<1 \quad$ : Tampak kurang dari 1 detik

$Y>1 \quad$ :Tampak lebih dari 1 detik

T : :Tidak tampak

Hasil jarak yang optimal pada penelitian yakni $10 \mathrm{~cm}$ dan $15 \mathrm{~cm}$, sehingga jarak tersebut dijadikan sebagai acuan untuk pengujian jarak geometri molekul yang dapat dilihat pada Tabel 4 ., dan Tabel 5 . Hasil pengujian jarak geometri molekul dapat tertangkap oleh kamera ponsel pada jarak $10 \mathrm{~cm}$ dan $15 \mathrm{~cm}$. Pada jarak $10 \mathrm{~cm}$ walaupun geometri molekul terbentuk tetapi objek terlihat sangat memenuhi layar ponsel karena kurangnya ruang pada layar tersebut, sehingga kurang maksimal ketika dilihat.

\subsection{Analisis Hasil}

Analisis ini dilakukan berdasarkan dengan metode alfa blackboxpada proses pendeteksian image target. Proses tahapantahapan pengujian mengenai image target dan berjalannya prototype AR Geometri Molekul telah dijabarkan di atas dengan berupa keterangan gambar dan juga table hasil uji coba. Tabel 6 dan Tabel 7 merupakan kesimpulan dari semua hasil uji yang telah diperoleh.

\section{Tabel 6. Hasil Pembentukan Marker Sebelum dimodifikasi}

\begin{tabular}{cclll}
\hline No & Senyawa & \multicolumn{1}{c}{ Hasil yang diharapkan } & \multicolumn{1}{c}{ Hasil Pengujian } & Kesimpulan \\
\hline 1. & $\mathrm{H}_{2} \mathrm{O}$ & $\begin{array}{l}\text { Sistem menampilkan objek } \mathrm{H}_{2} \mathrm{O} \text { dan } \\
\text { suara Air }\end{array}$ & $\begin{array}{l}\text { Sistem menampilkan objek } \mathrm{H}_{2} \mathrm{O} \text { pada saat } \\
\text { atom } \mathrm{H} \text { dan } \mathrm{O} \text { bertemu begitupun } \\
\text { sebaliknya }\end{array}$ & Tidak Sesuai \\
\hline 3. & $\mathrm{BeCl}_{2}$ & $\begin{array}{l}\text { Sistem menampilkan objek } \mathrm{BeCl}_{2} \text { dan } \\
\text { suara Berilium Chlorida }\end{array}$ & $\begin{array}{l}\text { Sistem menampilkan objek } \mathrm{BeCl}_{2} \text { pada } \\
\text { saat atom Be dan } \mathrm{Cl} \text { bertemu begitupun } \\
\text { sebaliknya }\end{array}$ & Tidak Sesuai \\
\hline 4. & $\mathrm{BF}_{3}$ & $\begin{array}{l}\text { Sistem menampilkan objek } \mathrm{BF}_{3} \text { dan } \\
\text { suara Boron Trifluorida }\end{array}$ & $\begin{array}{l}\text { Sistem menampilkan objek } \mathrm{BF}_{3} \text { pada saat } \\
\text { atom } \mathrm{B} \text { dan } \mathrm{F} \text { bertemu begitupun } \\
\text { sebaliknya }\end{array}$ & Tidak Sesuai \\
\hline 5. & $\mathrm{NH}_{3}$ & $\begin{array}{l}\text { Sistem menampilkan objek } \mathrm{NH}_{3} \text { dan } \\
\text { suara Amonia }\end{array}$ & $\begin{array}{l}\text { Sistem menampilkan objek } \mathrm{NH}_{3} \text { pada saat } \\
\text { atom } \mathrm{H} \text { dan } \mathrm{N} \text { bertemu begitupun } \\
\text { sebaliknya }\end{array}$ & Tidak Sesuai \\
& & & \\
\hline
\end{tabular}

Tabel 7. Hasil Pembentukan Marker Setelah dimodifikasi

\begin{tabular}{cclll}
\hline No & Senyawa & \multicolumn{1}{c}{ Hasil yang diharapkan } & \multicolumn{1}{c}{ Hasil Pengujian } & Kesimpulan \\
\hline 1. & $\mathrm{H}_{2} \mathrm{O}$ & $\begin{array}{l}\text { Sistem menampilkan objek } \mathrm{H}_{2} \mathrm{O} \text { dan } \\
\text { suara Air }\end{array}$ & $\begin{array}{l}\text { Sistem menampilkan objek } \mathrm{H}_{2} \mathrm{O} \text { geometri } \\
\text { bengkok dan suara Air saat 2 atom } \mathrm{H} \text { dan }\end{array}$ & Sesuai \\
& & O bertemu begitupun sebaliknya & \\
\hline 3. & $\mathrm{BeCl}_{2}$ & $\begin{array}{l}\text { Sistem menampilkan objek } \mathrm{BeCl}_{2} \text { dan } \\
\text { suara Berilium Chlorida }\end{array}$ & $\begin{array}{l}\text { Sistem menampilkan objek } \mathrm{BeCl} l_{2} \\
\text { geometri bengkok dan suara Berilium } \\
\text { Chlorida } \\
\text { saat 2 atom Cl dan Be bertemu begitupun } \\
\text { sebaliknya }\end{array}$ & Sesuai \\
& & & \\
\hline 4. & $\mathrm{BF}_{3}$ & $\begin{array}{l}\text { Sistem menampilkan objek } \mathrm{BF}_{3} \text { dan } \\
\text { suara Boron Trifluorida }\end{array}$ & $\begin{array}{l}\text { Sistem menampilkan objek } \mathrm{BF}_{3} \text { geometri } \\
\text { bengkok dan suara Boron Trifluorida saat }\end{array}$ & Sesuai \\
\hline
\end{tabular}




\begin{tabular}{|c|c|c|c|}
\hline & & $\begin{array}{l}3 \text { atom } F \text { dan B bertemu begitupun } \\
\text { sebaliknya }\end{array}$ & \\
\hline $\mathrm{NH}_{3}$ & $\begin{array}{l}\text { Sistem menampilkan objek } \mathrm{NH}_{3} \text { dan } \\
\text { suara Amonia }\end{array}$ & $\begin{array}{l}\text { Sistem menampilkan objek } \mathrm{NH}_{3} \text { geometri } \\
\text { bengkok dan suara } \mathrm{Amonia} \text { saat } 3 \text { atom } \mathrm{H} \\
\text { dan } \mathrm{N} \text { bertemu begitupun sebaliknya }\end{array}$ & Sesuai \\
\hline
\end{tabular}

Keterangan sesuai mengindikasi bahwa komponen yang terbentuk pada hasil yang diharapkan memiliki nilai yang benar atau sesuai, sehingga membuat sistem berjalan sesuai harapan. Sedangkan keterangan tidak sesuai mengindikasi bahwa komponen yg terbentuk pada hasil yang diharapkan memiliki nilai yang salah atau tidak sesuai. Skenario yang telah diujikan telah dilakukan 10 kali lebih percobaan dan dari semua percobaan menghasilkan hasil yang sama seperti yang terdapat pada tabel-tabel percobaan pengujian.

\section{KESIMPULAN}

Setelah melakukan implementasi, pengujian dan analisis mengenai aplikasi media pembelajaran interaktif geometri molekul kimia menggunakan Augmented Realityberbasis Android, maka penulis dapat memperoleh kesimpulan sebagai berikut

1. Dampak yang ditargetkan yaitu metode multimarker dapat digunakan pada aplikasi AR dalam pembelajaran materi geometri molekul kimia namun hasil yang didapatkan marker harus dimodifikasi terlebih dahulu karena metode ini tidak dapat menggunakan marker sejenis (marker yang sama) seperti hidrogen saja namun perlu dimodifikasi seperti marker hidrogen 1, hidrogen 2 dan hidrogen 3. Dengan begitu kelemahan penelitian ini yakni dibutuhkan marker yang banyak ketika akan membuat suatu rangkaian marker geometri molekul yang panjang.

2. Berdasarkan hasil pendekatan interaksi dengan IMSDD prototype AR geometri molekul kimia berhasil berjalan pada ponsel sesuai dengan mestinya. Hasil dari pengujian blackbox interaksi antar marker dapat terjadi dan membentuk geometri molekul. Interaksi tersebut ditandai dengan adanya perubahan dari beberapa atom ke molekul serta adanya suara atom dan suara molekul.

3. Berdasarkan hasil pengujian terhadap prototype aplikasi AR Geometri Molekul, bahwa aplikasi dapat berjalan dengan baik pada ponsel Android Xiaomi Note 4 dengan munculnya objek atom dan objek geometri molekul. Munculnya objek tersebut berdasarkan pengujian deteksi marker dibutuhkan presentase 50\%-100\% bagian marker yang terdeteksi oleh kamera ponsel untuk dapat menampilkan objek atom. Untuk uji jarak antara marker dan ponsel dipengaruhi dengan intensitas cahaya dan sudut kemiringan untuk menghasilkan objek atom dan objek geometri molekul. hasil uji yang ideal untuk pendeteksian marker pada intensitas cahaya 550 lux sejauh $10 \mathrm{~cm}$ sampai $20 \mathrm{~cm}$ dengan sudut kemiringan 0 sampai 30 derajat. Hasil uji yang ideal pada intensitas cahaya 1250 lux sejauh $10 \mathrm{~cm}$ sampai $20 \mathrm{~cm}$ dengan sudut kemiringan 0 sampai 45 derajat. Hasil uji yang ideal pada intensitas cahaya 8 lux sejauh $10 \mathrm{~cm}$ dengan sudut 0 sampai 30 derajat. Berdasarkan hasil uji tersebut diambil jarak $10 \mathrm{~cm}$ sampai $15 \mathrm{~cm}$ dengan sudut kemiringan 0 sampai 45 derajat pada intensitas cahaya 550 lux dan 1250 lux sebagai penggabungan ideal geometri molekul.

\section{DAFTAR PUSTAKA}

[1] I. L. Ismail, E. Enawaty, "Pengaruh penggunaan media pembelajaran videoscribe terhadap hasil belajar siswa materi ikatan kimia," Portal J. IIm. Univ. Tanjungpura, no. November, pp. 1-10, 2016.

[2] H. F. Nurdin, T. Sulastry, "Pengaruh Penggunaan Media Pembelajaran Berbasis Macromedia Flash 8 Pada Model Pembelajaran Kooperatif Melalui Pendekatan Saintifik Terhadap Motivasi Dan Hasil Belajar (Study Pada Materi Pokok Laju Reaksi)," Chem. Educ. Rev., vol. 1, no. 2, pp. 29-43, 2018.

[3] Admin, "Potensi Teknologi 'Augmented Reality' dan 'Virtual Reality' dalam Bisnis Digital," Universitas Indonesia, 2018. [Online]. Available: http://www.ui.ac.id/berita/potensi-teknologi-augmented-reality-danvirtual-reality-dalam-bisnis-digital.html. [Accessed: 20-Mar-2019].

[4] F. Manuri and A. Sanna, "A Survey on Applications of Augmented Reality," Adv. Comput. Sci. an Int. J., vol. 4, no. 1, pp. 2321-5157, 2016.

[5] T. R. Widodo, A. Setiawan, and S. Rostianingsih, "Pembuatan Aplikasi Pembelajaran 'Ikatan Kimia' dengan Memanfaatkan Augmented Reality," J. Infra, vol. 4, no. 2, pp. 126-129, 2016.

[6] M. A. G. Rajmah, M. Adrian, and M. B. Sanjaya, "Aplikasi AIChemist Menggunakan Augmented Reality Berbasis Android untuk Pembelajaran Kimia SMA," e-Proceeding Appl. Sci., vol. 3, no. 3, pp. 1448-1460, 
2017.

[7] P. Nikko, W. Hafidha, and E. Sudarmilah, "Augmented Reality Sistem Periodik Unsur Kimia Sebagai Media Pembelajaran Bagi Siswa Tingkat SMA Berbasis Android Mobile," KomuniTi, vol. VI, no. 2, pp. 122-131, 2014.

[8] S. Cai, X. Wang, and F. K. Chiang, "Erratum:A case study of Augmented Reality simulation system application in a chemistry course (Comput. Hum. Behav.(2014):37(31-40))," Comput. Human Behav., vol. 39, p. 424, 2014.

[9] Sugiyono, Metode Penelitian Kuantitatif, Kualitatif dan R\&D. Bandung: Alfabeta, 2016.

[10] Mohammad Dastbaz, Designing Interactive Multimedia System. New York: McGraw-Hil, 2003.

[11] Sugiyono, Metode Penelitian Pendidikan (Pendekatan Kuantitatif, Kualitatif, dan R\&D). Bandung: Alfabeta, 2013.

[12] Sukardi, Metodologi Penelitian Pendidikan(Kompetensi dan Praktiknya). Jakarta: Bumi Aksara, 2009. 